\title{
Brain and liver mitochondria isolated from diabetic Goto-Kakizaki rats show different susceptibility to induced oxidative stress
}

\author{
Maria S. Santos ${ }^{1}$ \\ Dario L. Santos ${ }^{2}$ \\ Carlos M. Palmeira ${ }^{1 *}$ \\ Raquel Seiça ${ }^{3}$ \\ António J. Moreno ${ }^{1}$ \\ Catarina R. Oliveira ${ }^{3}$ \\ ${ }^{1}$ Center for Neurosciences and Cell \\ Biology of Coimbra, Department of \\ Zoology, University of Coimbra, \\ Coimbra, Portugal \\ ${ }^{2}$ University of Trás os Montes e Alto \\ Douro, Vila Real, Portugal \\ ${ }^{3}$ Faculty of Medicine, University of \\ Coimbra, Coimbra, Portugal \\ *Correspondence to: C. Palmeira, \\ Center for Neurosciences and Cell \\ Biology of Coimbra, Department of \\ Zoology, University of Coimbra, \\ 3004-517 Coimbra, Portugal. \\ E-mail: palmeira@ci.uc.pt
}

\begin{abstract}
Background Increased oxidative stress and changes in antioxidant capacity observed in both clinical and experimental diabetes mellitus have been implicated in the etiology of chronic diabetic complications. Many authors have shown that hyperglycemia leads to an increase in lipid peroxidation in diabetic patients and animals reflecting a rise in reactive oxygen species production. The aim of the study was to compare the susceptibility of mitochondria from brain and liver of Goto-Kakizaki (12-month-old diabetic) rats (GK rats), a model of non-insulin dependent diabetes mellitus, to oxidative stress and antioxidant defenses.
\end{abstract}

Methods Brain and liver mitochondrial preparations were obtained by differential centrifugation. Oxidative damage injury was induced in vitro by the oxidant pair $\mathrm{ADP} / \mathrm{Fe}^{2+}$ and the extent of membrane oxidation was assessed by oxygen consumption, malondialdehyde (MDA) and thiobarbituric acid reactive substances (TBARS) formation. Coenzyme $Q$ and $\alpha$-tocopherol contents were measured by high-performance liquid chromatography (HPLC).

Results Brain mitochondria isolated from 12-month-old control rats displayed a higher susceptibility to lipid peroxidation, as assessed by oxygen consumption and formation of MDA and TBARS, compared to liver mitochondria. In GK rats, mitochondria isolated from brain were more susceptible to in vitro oxidative damage than brain mitochondria from normal rats. In contrast, liver mitochondria from diabetic rats were less susceptible to oxidative damage than mitochondria from normal rats. This decreased susceptibility was inversely related to their $\alpha$-tocopherol and coenzyme Q (CoQ) content.

Conclusions The present results indicate that the diabetic state can result in an elevation of both $\alpha$-tocopherol and CoQ content in liver, which may be involved in the elimination of mitochondrially generated reactive oxygen species. The difference in the antioxidant defense mechanisms in the brain and liver mitochondrial preparations of moderately hyperglycemic diabetic GK rats may correspond to a different adaptive response of the cells to the increased oxidative damage in diabetes. Copyright (C) 2001 John Wiley \& Sons, Ltd.

Keywords mitochondria; coenzyme Q; diabetes; oxidative stress; $\alpha$-tocopherol; Goto-Kakizaki rat 


\section{Introduction}

Diabetes is associated with an increased production of reactive oxygen species (ROS) in both humans and animals. Enhanced oxidative stress and changes in antioxidant capacity are considered to play an important role in the pathogenesis of chronic diabetic complications [1-4]. Evidence indicates that free oxygen radicals and membrane lipid peroxidation are significantly increased in diabetic patients and in rats used as models of diabetes [5-7]. Glucose autoxidation and non-enzymatic glycation of proteins are an important source of oxidative species, which may attack cellular components including nucleic acids, proteins and membrane lipids thus promoting cellular damage [3]. A decrease in the endogenous ROS scavenging compounds that normally protect cells from oxidative insults has also been observed in diabetic patients and animals [8,9].

Evidence associating diabetic pathology to mitochondrial dysfunction and oxidative stress has been reported previously [10-14]. Mitochondria are generally considered to be the major endogenous source of cellular ROS, under normal and pathological conditions, and perhaps of oxidative stress in general [15-17]. It has been estimated that during normal metabolism $1-2 \%$ of the electrons that flow into the redox chain catalyze the incomplete reduction of $\mathrm{O}_{2}$ generating superoxide anion and hydrogen peroxide. Under normal physiological conditions mitochondrial antioxidant systems (enzymatic and non-enzymatic) scavenge free radicals and preserve mitochondrial integrity [18]. Moreover, under certain pathophysiological conditions the generation of superoxide radical/hydrogen peroxide dramatically increases, leading to an imbalance between the pro-oxidant factors and the antioxidant systems. Since mitochondria are a major site of ROS generation and have a high concentration of heme and non-heme iron bound to proteins in addition to nucleotide-iron and carboxylic acid-iron complexes that can participate in Haber-Weiss reactions, the mitochondrial membrane is a primary target for ROS-induced damage [18]. The high content of polyunsaturated fatty acids in mitochondrial membranes enhances mitochondrial susceptibility to lipid peroxidation, leading to membrane dysfunction and alterations in the structural and functional integrity of the membrane [19]. As brain and liver heavily depend on mitochondrial oxidative catabolism for the majority of their ATP requirements, elevated levels of ROS are particularly dangerous because they mediate mitochondrial damage, which in turn can generate further oxidative stress in the cells [20].

The Goto-Kakizaki (GK) rat represents a non-obese animal model of type 2 diabetes [21] which was obtained by selective breeding of normal Wistar rats, using glucose intolerance as the selection index [22,23]. This genetic model is particularly relevant to understanding human type 2 diabetes since moderate but stable fasting hyperglycemia has been demonstrated as early as 2-4 weeks after birth, which does not progress to the ketotic state. Therefore, in the initial stages of diabetes GK rats do not present severe complications associated with the disease, and are thus an appropriate model in which to study the events at the onset of diabetes, as compared to obese diabetic rats which present severe hyperglycemia and hyperlipidemia [21].

There is currently considerable interest in the role of vitamin $\mathrm{E}$ and coenzyme Q (CoQ) compounds in the protection of membrane lipids against oxidative stress. CoQ is present in membranes with $\alpha$-tocopherols [24] and has been recognized as an important antioxidant in the inner mitochondrial membrane, where it scavenges radicals directly and/or regenerates $\alpha$-tocopherol from the $\alpha$-tocopheroxyl radical $[25,26]$. The possibility that CoQ content may be one of the factors controlling the susceptibility of mitochondria to oxidative stress in diabetic GK rats was examined. Data from our previous experiments have suggested that GK rats might develop enhanced defense systems against oxidative stress, which is believed to be an important factor in the development of diabetic complications [27]. The ADP/ $\mathrm{Fe}^{2+}$ was used to induce oxidative damage injury in isolated mitochondrial preparations and the extent of membrane oxidation was assessed by oxygen consumption, malondialdehyde (MDA) and thiobarbituric acid (TBA) reactive species formation. Furthermore, $\alpha$-tocopherol and $\operatorname{CoQ}\left(\mathrm{CoQ}_{9}\right.$ and $\mathrm{CoQ}_{10}$ ) contents were determined and studies were conducted to compare liver and brain mitochondrial susceptibility to oxidative stress and antioxidant defenses in both GK and Wistar rats.

\section{Materials and methods}

\section{Animals}

Male spontaneously diabetic GK rats (46-54 weeks of age; body weights $384.7 \pm 2.4 \mathrm{~g}$; non-fasting blood glucose levels $198.6 \pm 13.5 \mathrm{mg} / \mathrm{dl}$ ) were obtained from a local breeding colony of Coimbra, established in 1995 with breeding couples from the colony at the Tohoku University School of Medicine (Sendai, Japan; courtesy of Dr K. I. Susuki). Control animals were non-diabetic male Wistar rats of similar age (44-53 weeks of age; body weights $672.5 \pm 60.5 \mathrm{~g}$; non-fasting blood glucose levels $93.4 \pm 2.9 \mathrm{mg} / \mathrm{dl}$ ) obtained from our local colony. Animals were kept under controlled light and humidity conditions, and with free access to powdered rodent chow (diet CRF 20; Charles Rivers, France) and water. The animals were killed by decapitation and their livers and brains removed and washed in the respective homogenization medium.

\section{Materials}

Ubiquinone 10 was obtained from Fluka and ubiquinone 9 and $\alpha$-tocopherol were obtained from Sigma Chemical Co. (St Louis, MO, USA). All other chemicals used were of analytical grade. 


\section{Mitochondrial preparations}

Liver mitochondria were isolated according to a previously established method [28] with some modifications [29]. Homogenization medium contained $0.25 \mathrm{mM}$ sucrose, 5 mM Hepes (pH 7.4) 0.2 mM EGTA, $0.1 \mathrm{mM}$ EDTA and $0.1 \%$ de-fated bovine serum albumin (BSA). EGTA, EDTA and BSA were omitted from the final washing medium, adjusted to $\mathrm{pH}$ 7.2. The mitochondrial pellet was washed twice and suspended in washing medium.

Brain mitochondria (crude mitochondrial preparation) were isolated using the method of Lai and Clark [30]. All homogenization and centrifugation steps were performed in isolation medium $\left(0.32 \mathrm{mM}\right.$ sucrose, $1 \mathrm{mM} \mathrm{K}{ }^{+}$-EDTA, 5 mM Hepes-Tris, pH 7.4). After isolation, the mitochondrial suspensions of liver and brain were used after a $30 \mathrm{~min}$ recovery and within $4 \mathrm{~h}$ of preparation.

Mitochondrial protein was determined by the biuret method, using BSA as a standard.

\section{Measurement of lipid peroxidation}

Lipid peroxidation was determined as described by Sassa et al. [31]. The oxygen consumption was measured in $1 \mathrm{ml}$ of medium (175 mM KCl, $10 \mathrm{mM}$ Tris-Cl pH 7.4, supplemented with $3 \mu \mathrm{M}$ rotenone) containing $1 \mathrm{mg}$ protein, using a Clark-type electrode (YSI Model 5331; Yellow Springs Institute) in a glass chamber equipped with magnetic stirring and a thermostat set at $30^{\circ} \mathrm{C}$ [32]. Reactions were started by the addition of $1 \mathrm{mM}$ ADP and $0.1 \mathrm{mM} \mathrm{FeSO}_{4}$, after a 2-min incubation period. The saturated concentration of $\mathrm{O}_{2}$ in the incubation medium was assumed to be $232 \mu \mathrm{M}$ at $30^{\circ} \mathrm{C}$.

The extent of lipid peroxidation in the brain and liver mitochondria was also determined by measuring the amounts of thiobarbituric acid reactive substances (TBARS) and MDA formed by colorimetric assay and high-performance liquid chromatography (HPLC), respectively. The amount of TBARS formed was determined using the TBA test according to a modified procedure described by Ernster and Nordenbrand [33]. Mitochondrial protein $(1 \mathrm{mg} / \mathrm{ml})$ was incubated at $30^{\circ} \mathrm{C}$ for $15 \mathrm{~min}$, in a medium containing $175 \mathrm{mM} \mathrm{KCl,} 10 \mathrm{mM}$ Tris-Cl pH 7.4, supplemented with $3 \mu \mathrm{M}$ rotenone. Membrane lipid peroxidation was started by adding simultaneously $\mathrm{ADP} / \mathrm{FeSO}_{4}(1 \mathrm{mM} / 0.1 \mathrm{mM})$. The reaction was stopped by lowering the temperature to $0-4^{\circ} \mathrm{C}$ by placing the tubes in ice. To measure lipid peroxidation, $0.5 \mathrm{ml}$ cold $40 \%$ trichloroacetic acid and $2 \mathrm{ml} \mathrm{0.67 \%} \mathrm{TBA}$ containing $6.8 \mathrm{mM}$ 2,6-diterbutyl-4-methylphenol (BHT) were added to $0.5 \mathrm{ml}$ test material, which was then heated for $10 \mathrm{~min}$ in a boiling water bath and cooled on ice for $10 \mathrm{~min}$ before centrifugation in an Eppendorf centrifuge $(1500 \mathrm{~g}$ for $5 \mathrm{~min}$ ). The supernatants were collected and the absorbance measured at $535 \mathrm{~nm}$. The amount of TBARS formed was calculated using a molar extinction coefficient of $1.56 \times 10^{5} \mathrm{~mol}^{-1} \mathrm{~cm}^{-1}$ and expressed as nmol TBARS/mg protein [34].
The assay procedure used for MDA determination by HPLC was that of Wong et al. [35]. Liquid chromatography was performed using Gilson HPLC apparatus with a reverse phase column (RP18; Spherisorb; S5 $\mathrm{ODS}_{2}$ ). The samples were eluted from the column at a flow rate of $1 \mathrm{ml} / \mathrm{min}$ and detection was performed at $532 \mathrm{~nm}$. The MDA content of the samples was calculated from the standard curve prepared using the TBA-MDA complex and expressed in $\mathrm{nmol} / \mathrm{mg}$ protein.

\section{Extraction and quantification of CoQ and $\alpha$-tocopherol}

Aliquots of mitochondria containing $1 \mathrm{mg}$ protein/ml were extracted according to the method described previously [36]. The extract was evaporated to dryness under a stream of $\mathrm{N}_{2}$, and suspended in ethanol for HPLC analysis. Liquid chromatography was performed using Gilson HPLC apparatus with a reverse phase column (RP18; Spherisorb; S5 $\mathrm{ODS}_{2}$ ) as described previously [37]. Samples were eluted from the column with methanol: heptane (10:2 by volume) at a flow rate of $2 \mathrm{ml} / \mathrm{min}$. Detection was performed using a UV detector at $269 \mathrm{~nm}$. Identification and quantification were based on pure standards by their retention times and peak areas, respectively. The levels of $\mathrm{CoQ}\left(\mathrm{CoQ}_{9}\right.$ and $\left.\mathrm{CoQ}_{10}\right)$ in mitochondrial membranes were expressed in $\mathrm{pmol} / \mathrm{mg}$ protein.

The extraction and separation of $\alpha$-tocopherol were performed following the method described by Vatassery et al. [38]. The extract, evaporated to dryness under a stream of $\mathrm{N}_{2}$ and kept at -80C, was dissolved in $n$-hexane and $\alpha$-tocopherol content was analyzed by reverse phase HPLC. A $4.6 \times 200 \mathrm{~mm}$ Spherisorb S10w column was eluted with $n$-hexane modified with $0.9 \%$ methanol, at a flow rate of $1.5 \mathrm{ml} / \mathrm{min}$. Detection was performed using a UV detector at $287 \mathrm{~nm}$. The levels of vitamin $\mathrm{E}$ in mitochondrial membranes were expressed in $\mathrm{pmol} / \mathrm{mg}$ protein.

\section{Data analysis and statistics}

Data are expressed as means \pm SEM of the indicated number of experiments, each obtained with a different animal. Statistical significance was determined by using the paired Student's $t$-test and by using the one-way ANOVA Student-Newmann-Keuls post-test for multiple comparisons. A $p$ value $<0.05$ was considered significant.

\section{Results}

\section{Oxidative stress induced by $\mathrm{ADP} / \mathrm{Fe}^{2+}$}

Brain mitochondria displayed a higher susceptibility to lipid peroxidation induced by $\mathrm{ADP} / \mathrm{Fe}^{2+}$, as assessed by oxygen consumption and the formation of TBARS, as compared to liver mitochondria (Figures 1 and 2). As shown in Figure 1, the time-dependent change in the 

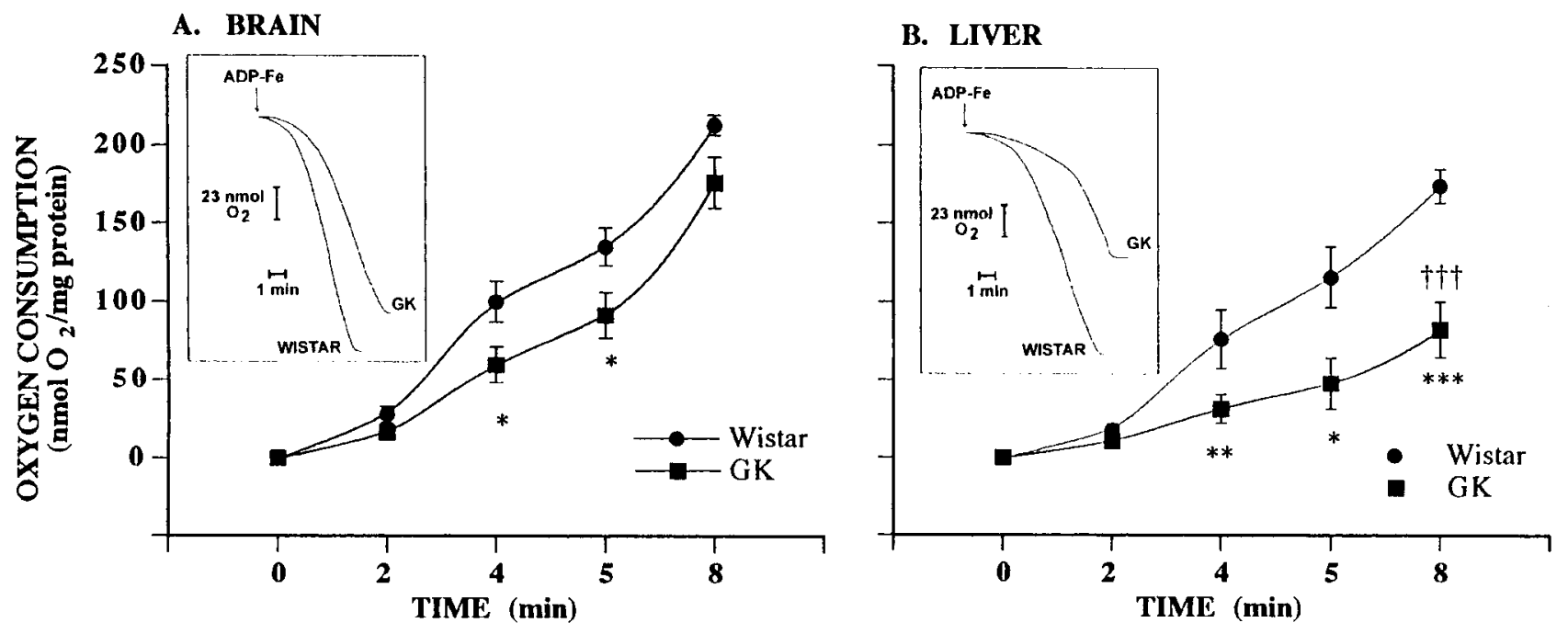

Figure 1. Comparison of $\mathrm{ADP} / \mathrm{Fe}^{2+}$-induced mitochondrial $\mathrm{O}_{2}$ consumption in rat brain (A) and liver (B) mitochondria isolated from Wistar and GK rats. Oxidative stress was induced in mitochondria isolated from the brains or livers of control and diabetic rats. Mitochondria $(1 \mathrm{mg}$ ) were incubated in $1 \mathrm{ml}$ medium consisting of $175 \mathrm{mM} \mathrm{KCl}, 10 \mathrm{mM}$ Tris ( $\mathrm{pH} 7.4$ ), for $30 \mathrm{~min}$ at $30^{\circ} \mathrm{C}$, supplemented with $2 \mu \mathrm{M}$ rotenone. Peroxidation was started by adding $1 \mathrm{mM}$ ADP and $0.1 \mathrm{mM} \mathrm{FeSO}$. The inserts represent typical recordings of oxygen consumption. Data are the means \pm SEM of seven different experiments. Statistical significance: ${ }^{* * *} p<0.001, * * p<0.01$ or $* p<0.05$ as compared to control Wistar rats; ${ }^{* \dagger} p<0.001$ as compared to brain mitochondria

peroxidation related to oxygen concentrations in the suspensions of brain and liver mitochondria are different in preparations isolated from diabetic rats as compared to control rats. In diabetic mitochondria, at first slow oxygen consumption occurs for a few minutes after the addition of $\mathrm{ADP} / \mathrm{Fe}^{2+}$ and then the consumption of oxygen increases. In addition, when mitochondria of GK rats did begin to peroxidize they did so at a slower rate than control mitochondria. The time associated with the slow

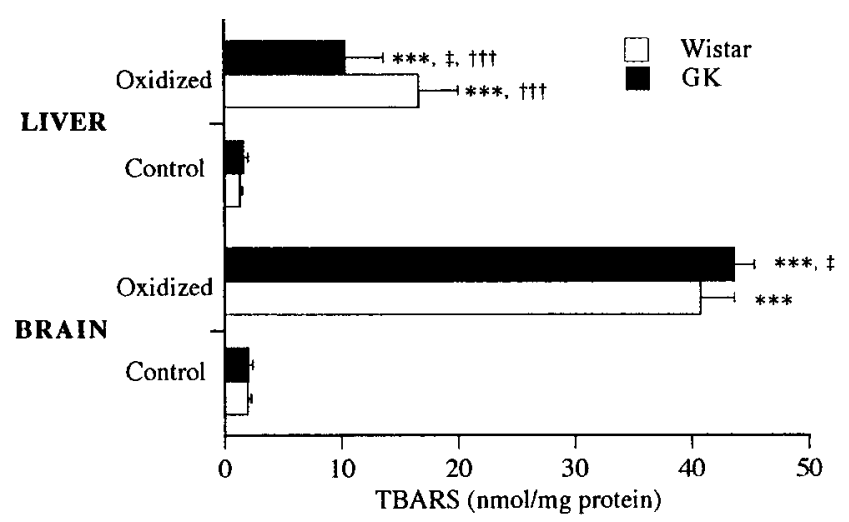

Figure 2. Effect of diabetes on the extent of mitochondrial oxidation induced by $\mathrm{ADP} / \mathrm{Fe}^{2+}$. Mitochondria $(1 \mathrm{mg})$ were incubated in $1 \mathrm{ml}$ medium consisting of $175 \mathrm{mM} \mathrm{KCl}, 10 \mathrm{mM}$ Tris ( $\mathrm{pH} 7.4$ ), for $30 \mathrm{~min}$ at $30^{\circ} \mathrm{C}$, supplemented with $2 \mu \mathrm{M}$ rotenone. Peroxidation was started by adding $1 \mathrm{mM}$ ADP and $0.1 \mathrm{mM} \mathrm{FeSO}_{4}$. In controls mitochondria were incubated in the absence of the oxidizing agents. The extent of synaptosomal oxidation was determined by the TBA method and expressed as $\mathrm{nmol} / \mathrm{mg}$ protein. Data are the means \pm SEM of seven experiments run in duplicate. Statistical significance: $* * * p<0.001$ as compared to respective controls not treated with $\mathrm{ADP} / \mathrm{Fe}^{2+} ;{ }^{\dagger} p<0.05$ as compared to Wistar mitochondria treated with $\mathrm{ADP} / \mathrm{Fe}^{2+} ;{ }^{\dagger \dagger} p<0.001$ as compared to data obtained for oxidized brain mitochondria oxygen consumption that follows the addition of ADP/ $\mathrm{Fe}^{2+}$ until the rapid oxygen uptake (lag time) is considered to be the time required for the generation of a sufficient amount of reactive oxygen species derived from $\mathrm{ADP} / \mathrm{Fe}^{2+}$, such as the perferryl complex ADP- $-\mathrm{Fe}^{3+}$ $\mathrm{O}_{2}{ }^{-}-$responsible for the induction of lipid peroxidation. The rapid oxygen consumption after the lag phase follows the peroxidative radical chain proliferation of membrane lipids by ROS.

Figure 2 shows that in the absence of oxidants the levels of TBARS were similar in brain and liver mitochondria isolated from control $(1.97 \pm 0.31$ and $1.33 \pm 0.23 \mathrm{nmol} / \mathrm{mg}$ protein, respectively) or GK rats $(2.03 \pm 0.37$ and $1.67 \pm 0.36 \mathrm{nmol} / \mathrm{mg}$ protein, respectively). In control rats the oxidation by $\mathrm{ADP} / \mathrm{Fe}^{2+}$ increased significantly the production of TBARS in brain and liver to $40.77 \pm 2.9$ and $16.66 \pm 3.36 \mathrm{nmol} / \mathrm{mg}$ protein, respectively. A significant increase in the extent of oxidation was observed in mitochondria isolated from the brains of GK rats as compared with mitochondria from Wistar rats. In contrast, liver mitochondria from diabetic rats were less susceptible to oxidative damage than mitochondria from normal rats.

As the validity of the TBA test for the assessment of lipid peroxidation has been questioned many times [39], the formation of lipid peroxides (as MDA) was also measured by a more specific HPLC method. The results obtained indicated that this procedure yielded lower values of MDA in control and oxidized mitochondria when compared to the respective TBARS values (Table 1 and Figure 2). In Wistar rats, $\mathrm{ADP} / \mathrm{Fe}^{2+}$ increased the formation of MDA in brain and liver to $10.89 \pm 0.37$ and $11.97 \pm 0.17 \mathrm{nmol}$ $\mathrm{MDA} / \mathrm{mg}$ protein, respectively, values significantly different from those determined in control conditions $(1.80 \pm 0.35$ and $1.14 \pm 0.18 \mathrm{nmol} \mathrm{MDA} / \mathrm{mg}$ protein, 
Table 1. Levels of MDA in brain and liver mitochondria oxidized with $\mathrm{ADP} / \mathrm{Fe}^{2+}$

\begin{tabular}{lcc}
\hline Experimental condition & Brain & Liver \\
\hline Wistar rats & & \\
$\quad$ Control & $1.80 \pm 0.35$ & $1.14 \pm 0.18$ \\
$\quad$ Oxidized & $10.89 \pm 0.37^{* * *}$ & $11.97 \pm 0.17^{* * *}$ \\
GK rats & $1.34 \pm 0.34$ & $0.44 \pm 0.11 \S$ \\
$\quad$ Control & $12.44 \pm 0.40^{* * * \hbar}$ & $9.91 \pm 0.36^{* * * \dagger \dagger}$ \\
$\quad$ Oxidized & \\
\hline
\end{tabular}

The experimental conditions were similar to those described in the legend to Figure 2. MDA levels were determined by HPLC and were expressed as nmol $\mathrm{MDA} / \mathrm{mg}$ protein. Data are the means \pm SEM from three different samples, each obtained from a different rat. Statistical significance: ${ }^{* *} p<0.001$ as compared to respective controls not treated with $\mathrm{ADP} / \mathrm{Fe}^{2+} ; \xi p<0.05$ as compared to respective Wistar control; ${ }^{\dagger \dagger} p<0.001$ and ${ }^{t} p<0.05$ as compared to Wistar mitochondria treated with $\mathrm{ADP} / \mathrm{Fe}^{2+}$.

respectively). A significant increase in MDA formation was observed in brain mitochondria isolated from GK rats submitted to $\mathrm{ADP} / \mathrm{Fe}^{2+}(12.44 \pm 0.40 \mathrm{nmol} / \mathrm{mg}$ protein) as compared with mitochondria from Wistar rats $(10.89 \pm 0.39 \mathrm{nmol} / \mathrm{mg}$ protein). The levels of MDA in control and oxidized liver mitochondria from GK rats $(0.44 \pm 0.11$ and $9.91 \pm 0.36 \mathrm{nmol} / \mathrm{mg}$ protein, respectively) were lower than those in Wistar mitochondria $(1.14 \pm 0.18$ and $11.97 \pm 0.17 \mathrm{nmol} / \mathrm{mg}$ protein, respectively; Table 1).

\section{CoQ and $\alpha$-tocopherol content in mitochondria}

CoQ in rat mitochondria consisted of two main homologues, $\mathrm{CoQ}_{9}$ and $\mathrm{CoQ}_{10}$. In the brains of control Wistar rats, $\mathrm{CoQ}_{9}$ represented about $80 \%$ and $\mathrm{CoQ}_{10} 20 \%$ of the total amount of mitochondrial CoQ $(1.14 \pm 0.07 \mathrm{nmol} / \mathrm{mg}$ protein). In liver mitochondria, $\mathrm{CoQ}_{9}$ constituted about $97 \%$ of the total CoQ content $(0.89 \pm 0.04 \mathrm{nmol} / \mathrm{mg}$ protein). Brain mitochondria of GK and control Wistar rats contained similar levels of $\alpha$-tocopherol, but the $\mathrm{CoQ}_{9}$ content in the GK mitochondria was lower than that in the Wistar mitochondria. In contrast, there was a remarkable increase of about $100 \%$ in the $\alpha$-tocopherol and CoQ content in the liver mitochondria isolated from diabetic rats as compared to control rats (Figures 3 and 4). In brain and liver the changes in $\mathrm{CoQ}_{9}$ content paralleled that of the total CoQ content (Figure 4).

\section{Discussion}

One of the main findings of the present study was the observation of differential content of CoQ and $\alpha$-tocopherol in mitochondria isolated from diabetic animals. Thus, diabetes increased the levels of CoQ and $\alpha$-tocopherol in liver mitochondria isolated from diabetic GK rats but not in brain mitochondria. A small decrease in CoQ content was observed in brain mitochondria. Another point of interest was the observation that there is an inverse correlation between the levels of the antioxidants

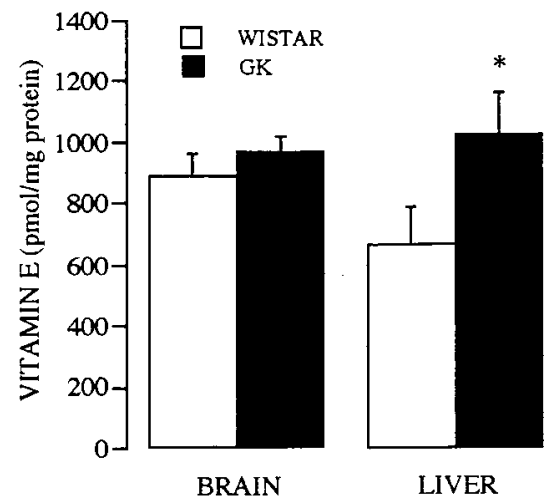

Figure 3. Vitamin E levels in brain and liver mitochondria isolated from Wistar and GK rats. Vitamin E ( $\alpha$-tocopherol) was measured by reverse-phase HPLC as described in Materials and methods. The data are the mean \pm SEM for seven different samples, each obtained from a different rat. Statistical significance: * $p<0.05$ as compared to the levels of vitamin $\mathrm{E}$ in control Wistar rats

$\alpha$-tocopherol and CoQ and the susceptibility of mitochondria to oxidative damage induced by $\mathrm{ADP} / \mathrm{Fe}^{2+}$.

Many authors have associated hyperglycemia-induced changes in oxidative state with diabetic complications. Evidence for oxidative stress in diabetes includes reports of increased free radical generated plasma lipid peroxides and observations of decreased antioxidant plasma concentrations in both humans and animal models of diabetes [7]. Although, the concentrations of vitamin $\mathrm{E}$ in plasma and in tissues, in both diabetic patients and experimental diabetes, are controversial, an inverse association between serum $\alpha$-tocopherol concentration and subsequent occurrence of the disease has been

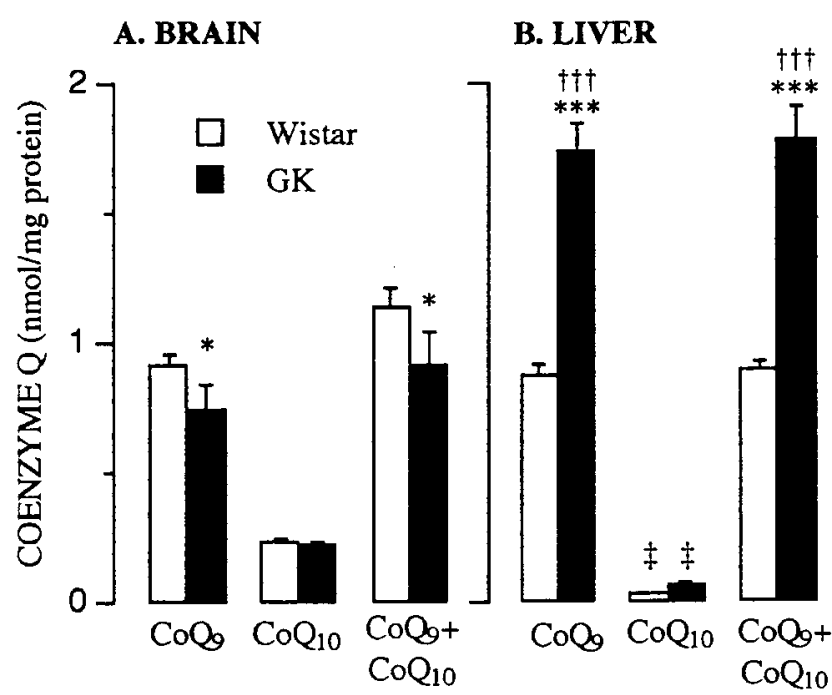

Figure 4. Coenzyme $Q_{9}$ and $Q_{10}$ levels in brain and liver mitochondria isolated from Wistar and GK rats. Coenzyme Q levels were measured by HPLC as described in Materials and methods. Data are the means \pm SEM for seven different samples, each obtained from a different rat. Statistical significance: $* * * p<0.001$ or $* p<0.05$ as compared to control Wistar rats; ${ }^{\dagger \dagger} p<0.005$ as compared to GK brain mitochondria; ${ }^{\dagger}<0.005$ as compared to brain values 
reported [40]. A beneficial effect of vitamin $\mathrm{E}$ on the complications of diabetes was also reported [41-43].

An increase in $\alpha$-tocopherol might be expected to render the mitochondria more resistant to in vitro lipid peroxidation. This is illustrated by the time course experiments on oxygen consumption. Diabetes induced a significant increase in the initiation phase of the lipid peroxidation analyzed as the lag time that accompanies the oxygen uptake burst. In addition the mitochondrial fractions of GK peroxidized slowly as compared to the controls. The observed increase in the lag phase and the decrease in oxygen consumption, TBARS and MDA formation are probably due to the higher content of $\alpha$-tocopherol in GK diabetic animals. It has been observed that liver microsomes from vitamin-E deficient rats peroxidized at a greater rate than control microsomes [44]. Vitamin E ( $\alpha$-tocopherol) is well established as one of the most important lipid-soluble, chain reactionbreaking antioxidants protecting the integrity of lipid structures in membranes against oxidative damage [45]. Increased levels of vitamin $\mathrm{E}$ in liver $[12,46]$ and heart $[46,47]$ of streptozotocin-treated diabetic rats and in brain membranes of $\mathrm{db} / \mathrm{db}$ mice [48] have been reported. Sukalski et al. [12] suggested that the increased vitamin $\mathrm{E}$ levels associated with diabetes may be due to alterations in the metabolism and storage of vitamin $\mathrm{E}$. The elevation of vitamin $\mathrm{E}$ content in membranes may be partially explained by the fact that plasma vitamin $\mathrm{E}$ may be increased by mobilization with lipids from the adipose tissue and the liver to other tissues [12]. Besides its effects linked to antioxidative properties, vitamin $\mathrm{E}$ has been shown to reduce protein glycosylation both in vivo and in vitro $[49,50]$ and to improve insulin action in nondiabetic and non-insulin-dependent diabetic patients [51] and $\beta$-cell function [52]. Vatassery et al. [37] found that plasma and platelet vitamin $\mathrm{E}$ levels were higher in patients with types 1 and 2 diabetes as compared to the control group.

In recent years there has been considerably interest in the protective role of CoQ against oxidative stress. Besides its well-established function as a component of the mitochondrial respiratory chain, in its reduced form CoQ may function as an antioxidant, protecting membrane phospholipids and serum low-density lipoprotein from lipid peroxidation by quenching lipid radicals or lipid peroxidation initiating species and, as recent data indicate, it also protects mitochondrial membrane proteins and DNA from free radical-induced oxidative damage $[25,26,53]$. These effects seem to be independent of those of exogenous antioxidants, such as vitamin E, although CoQ can also potentiate the effect of $\alpha$-tocopherol by regenerating it from its oxidized form [54]. Coenzyme $Q$ is endogenously synthesized in most mammalian cells and organs and its levels in membranes are regulated, through the mevalonate pathway, by physiological factors that are related to oxidative activity of the organism. Evidence that the increase in CoQ content occurred after the increase in metabolic rate, and thus free radical production (e.g. during physical exercise, cold adaptation or thyroid hormone treatment) suggests that the increase in CoQ may an adaptation to or a response to, rather than a cause of, increased oxidative activity [25,54]. Boveris et al. [55] have also shown that CoQ levels significantly increased in liver mitochondria isolated from rats made diabetic by pancreatectomy. It is interesting to note that the increase in CoQ content in liver mitochondria of GK rats may be related to the increased efficiency of mitochondrial FAD-linked glycerol3-phosphate dehydrogenase, the key enzyme in the glycerol phosphate shuttle, and to an increased efficiency rate of oxidative metabolism, as a result of the increased efficiency in the oxidative phosphorylation of diabetic rats as compared with control animals, features that are exclusive to the liver $[56,57]$. This may explain why CoQ levels increase in diabetes only in the liver and not in brain mitochondria.

The present results constitute the first evidence for possible differential metabolism of $\mathrm{CoQ}$ in diabetic animals and augment earlier reports on the higher content of $\alpha$-tocopherol in several preparations isolated from diabetic animals. The simultaneous increase of CoQ and $\alpha$-tocopherol in rat liver mitochondria isolated from GK rats suggests an interaction between CoQ and $\alpha$-tocopherol. Sohal and colleagues reported recently that the recycling of $\alpha$-tocopherol in mitochondrial membranes is directly dependent of the molar ratios of $\alpha$-tocopherol and CoQ $[58,59]$. In fact, and in contrast to liver mitochondria, an insufficient amount of CoQ may explain why the levels of $\alpha$-tocopherol in brain mitochondria were unchanged in GK diabetic animals. Recent studies have indicated that the generation of superoxide anion by submitochondrial particles was inversely related to their $\alpha$-tocopherol content and unrelated to CoQ, and that the antioxidative role of CoQ in mitochondria may be due to a 'sparing/regenerating effect' of CoQ on $\alpha$-tocopherol rather than a direct effect as radical scavenger [58,60-62].

In conclusion, the present findings show that liver preparations of diabetic GK rats were more resistant to oxidative stress than those of control rats, supporting the idea that the liver may be protected from the injury induced by radical species involved in diabetic complications. The significant increase in vitamin $\mathrm{E}$ and $\mathrm{CoQ}$ in liver of GK rats is consistent with the observed decreased in the susceptibility to in vitro lipid peroxidation. Since some of the important biochemical reactions determining the metabolic disorders observed in diabetes are localized in liver mitochondria, and the liver is a central organ in glucose homeostasis, the observed increase in antioxidant defenses and decreased susceptibility to oxidative stress in GK liver mitochondria could have developed as a biochemical response or as an adaptation to metabolic disturbances associated with type 2 diabetes. The difference in the antioxidant defense mechanisms in the brain and liver mitochondrial preparations of moderately hyperglycemic diabetic GK rats may correspond to a different adaptive response of the cells to the increased oxidative damage in diabetes. 


\section{Acknowledgements}

We thank Professor Luís Rosário (Department of Biochemistry, University of Coimbra) for all the facilities connected with the use of GK rats, and Professor João Patrício and co-workers (Laboratory of Animal Research Center, University Hospitals, Coimbra) for their help in the maintenance of animals. We would also like to thank Dr Teresa Proença (Laboratory of Neurochemistry, University Hospitals, Coimbra) for the analysis of MDA, and Dr Fernanda Nobre for her technical assistance in the determination of coenzyme $\mathrm{Q}$ content. This research was supported by grants from the FCT (Portuguese Research Council; research project PRAXIS/SAU/1/96).

\section{References}

1. Oberley LW. Free radicals and diabetes. Free Radic Biol Med 1988; 5: 113-124.

2. Baynes JW. Role of oxidative stress in development of complications in diabetes. Diabetes 1991; 40: 405-412.

3. Wolff SP, Jiang JY, Hunt JV. Protein glycation and oxidative stress in diabetes mellitus and ageing. Free Radic Biol Med 1991; 10: 339-352.

4. Baynes JW, Thorpe R. Role of oxidative stress in diabetic complications. A new perspective on an old paradigm. Diabetes 1999; 48: 1-9.

5. Altomare E, Vendemiale G, Chicco D, Procacci V, Cirelli F. Increased lipid peroxidation in type 2 poorly controlled diabetic patients. Diabetes Metab 1992; 18: 264-271.

6. Gallou G, Ruelland A, Legras B, Mangendre D, Allanic H, Cloarec L. Plasma malondialdehyde in type 1 and type 2 diabetic patients. Clin Chim Acta 1993; 214: 227-239.

7. VanDam PS, Bravenboer B. Oxidative stress and antioxidant treatment in diabetic neuropathy. Neurosci Res Commun 1997; 21: $41-48$.

8. Wohaieb S, Godin DV. Alterations in free radical tissue defense mechanisms in streptozotocin-induced diabetes in rat. Diabetes 1987; 36: 1014-1018.

9. Aguirre F, Martin T, Grinspon D, et al. Oxidative damage, plasma antioxidant capacity and glycemic control in elderly NIDDM patients. Free Radic Biol Med 1998; 24: 580-585.

10. Hall JC, Sordhal LA, Stefko PL. The effect of insulin on oxidative phosphorylation in normal and diabetic mitochondria. $J$ Biol Chem 1960; 253: 1536-1539.

11. Wallace DC. Mitochondrial genetics: a paradigm for aging and degenerative diseases. Science 1992; 256: 628-632.

12. Sukalski KA, Pinto KA, Berntson JL. Decreased susceptibility of liver mitochondria from diabetic rats to oxidative damage and associated increase in $\alpha$-tocopherol. Free Radic Biol Med 1993; 14: 57-65.

13. Kristal BS, Jackson CT, Chung HY, Matsuda M, Nguyen HD, Yu BP. Defects at the center $\mathrm{P}$ underlie diabetes-associated mitochondrial dysfunction. Free Radic Biol Med 1997; 22: 823-833.

14. Anderson CM. Mitochondrial dysfunction in diabetes mellitus. Drug Dev Res 1999; 46: 67-79.

15. Ames BN, Shigenaga MK, Hagen TM. Oxidants, anti-oxidants, and the degenerative diseases of aging. Proc Natl Acad Sci U S A 1993; 90: 7915-7922.

16. Nohl H. Generation of superoxide radicals as byproduct of cellular respiration. Ann Biol Clin 1994; 52: 199-204.

17. Cortopassi GA, Wong A. Mitochondria in organismal aging and degeneration. Biochem Biophys Acta 1999; 1410: 183-193.

18. Radi R, Castro L, Rodriguez M, Cassina A, Thomson L. Free radical damage to mitochondria. In Mitochondria and Free Radicals in Neurodegenerative Diseases, Beal MF, Howell N, Bodis-Wollner I (eds). Wiley-Liss: New York, NY, 1997; 57-89.

19. Rice-Evans C, Gordon R. Free radical-lipid interactions and their pathological consequences. Free Radic Biol Med 1993; 32: 71-110.

20. Nohl H, Staniek K, Gille L. Imbalance of oxygen activation and energy metabolism as a consequence or mediator of aging. Exp Gerontol 1997; 32: 485-500.
21. McIntosh CHS, Pederson RA. Noninsulin-dependent animal models of diabetes mellitus. In Experimental Models of Diabetes, McNeill JH (ed.). CRC Press: Boca Raton, FL 1999; 337-398.

22. Goto Y, Kakizaki M. The spontaneous diabetic rat: a model of non-insulin dependent diabetes mellitus. Proc Jpn Acad 1981; 57: 381-384.

23. Goto Y, Suzuki K-I, Sasaki M, Toyota T. Development of diabetes in the non-obese NIDDM rat (GK rat). Adv Exp Med Biol 1988; 246: 29-31.

24. Cadenas EP, Hochstein P, Ernster L. Pro-and antioxidant functions of quinones and quinones reductases in mammalian cells. In Advances in Enzymology and Related Areas of Molecular Biology, vol. 65, Meister A (ed.). John Wiley \& Sons: New York, NY, 1992; 97-146.

25. Ernster L, Dallner G. Biochemical, physiological and medicinal aspects of ubiquinone function. Biochim Biophys Acta 1995; 1271: 195-204.

26. Lenaz G. Role of mitochondria in oxidative stress and ageing. Biochim Biophys Acta 1998; 1366: 53-67.

27. Ferreira FML, Palmeira CM, Matos MJ, Seiça R, Santos MS. Decreased susceptibility to lipid peroxidation of Goto-Kakizaki rats: relationship to mitochondrial antioxidant capacity. Life Sci 1999; 65: 1013-1025.

28. Gazotti P, Malmstron K, Crompton M. A Laboratory Manual on Transport and Bioenergetics, Carafoli E, Semenza G (eds). Springer-Verlag: New York, 1972; 62-69.

29. Ferreira FML, Madeira VMC, Moreno AJ. Interaction of 2,2-bis ( $p$-chlophenyl)-1,1-dichloroethylene with mitochondrial oxidative phosphorylation. Biochem Pharmacol 1997; 53: 299-308.

30. Lai JCK, Clark JB. Preparation of synaptic and non-synaptic mitochondria from mammalian brain. Methods Enzymol 1979 55: 51-60.

31. Sassa H, Takaishi Y, Terada H. The triterpene celastrol as a very potent inhibitor of lipid peroxidation in mitochondria. Biochem Biophys Res Commun 1990; 172: 890-897.

32. Santos MS, Duarte AI, Moreira PI, Oliveira CR. Synaptosomal response to oxidative stress: effect of vinpocetine. Free Radic Res 2000; 32: 57-66.

33. Ernster L, Nordenbrand K. Microsomal lipid peroxidation. Methods Enzymol 1967; 10: 574-580.

34. Buege JA, Aust S. Microsomal lipid peroxidation. Methods Enzymol 1978; 52: 302-310.

35. Wong SHY, Knight JA, Hopfer SM, Zaharia O, Leach CN, Sunderman FW. Lipoperoxides in plasma as measured by liquidchromatographic separation of malondialdeyde-thiobarbituric acid adduct. Clin Chem 1987; 33: 214-220.

36. Takada M, Ikenoya S, Yuzuriha T, Katayama K. Simultaneous determination of reduced and oxidized ubiquinones. Methods Enzymol 1984; 105: 147-155.

37. Chung AP, Rainey F, Nobre MF, Burghardt J, Costa MS Meiothermus cerbereus sp. nov., a new slightly thermophilic species with high levels of e-hydroxy fatty acids. Int $J$ Syst Bact 1997; 47: 1225-1230.

38. Vatassery GT, Morley JE, Kuskowski MA. Vitamin E in plasma and platelets of human diabetic patients and control subjects. Am J Clin Nutr 1983; 37: 641-644.

39. Esterbauer H, Cheeseman KH. Determination of aldehydic lipid peroxidation products: malonaldeyde and 4-hydroxynonenal. Methods Enzymol 1990; 186: 407-421.

40. Knekt P, Reunanen A, Marniemi J, Leino A, Aromaa A. Low vitamin $\mathrm{E}$ status is a potential risk factor for insulin-dependent diabetes mellitus. J Int Med 1999; 245: 99-102.

41. Cotter MA, Love A, Watt MJ, Cameron ME, Dines KC. Effects of natural free radical scavengers on peripheral nerve and neurovascular function in diabetic rats. Diabetologia 1995; 38 : 1285-1294.

42. Keegan A, Walbank H, Cotter MA, Cameron NE. Chronic vitamin $\mathrm{E}$ treatment prevents defective endothelium-dependent relaxation in diabetic rat aorta. Diabetologia 1995; 38: 1475-1478.

43. Kunisaki M, Bursell SE, Clermomt AC, et al. Vitamin E prevents diabetes-induced abnormal retinal blood flow via the diacylglycerol-protein kinase C pathway. Am J Physiol 1995; 269: E239-E246.

44. Cadenas E, Ginsberg M, Rabe U, Sies H. Evaluation of alphatocopherol antioxidant activity in microsomal lipid peroxidation as detected by low-level chemiluminescence. Biochem $J$ 1984; 223: 755-759.

45. Banks MA. In Oxidants, Antioxidants, and Free Radicals, Baskin 
SI, Salem H (eds). Taylor \& Francis, Washington, DC, 1997; 95-111.

46. Sun F, Iwaguchi $\mathrm{K}$, Shudo $\mathrm{R}$, et al. Change in tissue concentrations of lipid hydroperoxides, vitamin $\mathrm{C}$ and vitamin E in rats with streptozotocin-induced diabetes. Clin Sci 1999; 96: 185-190.

47. Jain SK, Levine SN. Elevated lipid peroxidation and vitamin E-quinone levels in heart ventricles of streptozotocin-treated diabetic rats. Free Radic Biol Med 1999; 18: 337-341.

48. Makar TK, Rimpel-Lamhaouar K, Abraham DG, Gokhale S, Cooper AJL. Antioxidant defense systems in the brains of type II diabetic mice. $J$ Neurochem 1995; 65: 287-291.

49. Ceriello A, Giugliano D, Quatraro A, Donzella C, Dipalo G, Lefbvre PJ. Vitamin E reduction of protein glycosylation in diabetes - new prospect for prevention of diabetic complications? Diabetes Care 1991; 14: 68-72.

50. Ceriello A, Quatraro A, Giugliano D. New insights on nonenzymatic glycosylation may lead to therapeutic approaches for the prevention of diabetic complications. Diabet Med 1992; 9: 297-299.

51. Paolisso G, D’Amore A, Giugliano D, Ceriello A, Varricchio M, D'Ónofrio F. Pharmacologic doses of vitamin E improve insulin action in healthy subjects and non-insulin-dependent diabetic patients. Am J Clin Nutr 1993; 57: 650-656.

52. Tajiri Y, Grill VE. Interactions between vitamin $\mathrm{E}$ and glucose on $\beta$-cell functions in the rat: an in vivo and in vitro study. Pancreas 1999; 18: 274-281.

53. Beyer RE. The participation of coenzyme $Q$ in free radical production and antioxidation. Free Radic Biol Med 1990; 8: 545-565.

54. Kagan VE, Serbinova EA, Packer L. Antioxidant effects of ubiquinone in microsomes and mitochondria are mediated by tocopherol recycling. Biochem Biophys Res Commun 1990; 169 851-857.

55. Boveris AA, Ramos MCP, Stoppani AOM, Foglia VG. Phosphorylation, oxidation and ubiquinone content in diabetic mitochondria. Proc Soc Exp Biol Med 1969; 132: 170-174.

56. Ostenson CG, Abdel-Halim SM, Rasschaert J, et al. Didicient activity of FAD-linked glycerophosphate dehydrogenase in islets of GK rats. Diabetologia 1993; 36: 722-726.

57. Palmeira CM, Ferreira FML, Santos DL, Seiça R, Suzuki K, Santos MS. Higher efficiency of the liver in diabetic Goto-Kakizaki (GK) rats. FEBS Lett 1999; 458: 103-106.

58. Lass A, Sohal S. Electron transport-linked ubiquinonedependent recycling of $\alpha$-tocopherol inhibits autooxidation of mitochondrial membranes. Arch Biochem Biophys 1998; 352: 229-236.

59. Lass A, Sohal RS. Effect of coenzyme Q10 and $\alpha$-tocopherol content of mitochondria on the production of superoxide anion radicals. FASEB $J$ 2000; 14: 87-94.

60. Maguire JJ, Kagan V, Ackrell BA, Serbinova E, Packer L. Succinate-ubiquinone reductase linked recycling of alphatocopherol in reconstituted systems and mitochondria: requirements for reduced ubiquinone. Arch Biochem Biophys 1992; 292: 47-53.

61. Stoyanovsky DA, Osipov AN, Quinn PJ, Kagan VE. Ubiquinonedependent recycling of vitamin $\mathrm{E}$ radicals by superoxide. Arch Biochem Biophys 1995; 323: 343-351.

62. Lass A, Forster MJ, Sohal RS. Effects of coenzyme Q10 and $\alpha$-tocopherol administration on their tissue levels in the mouse: elevation of mitochondrial $\alpha$-tocopherol by coenzyme Q10. Free Radic Biol Med 1999; 26: 1375-1382. 